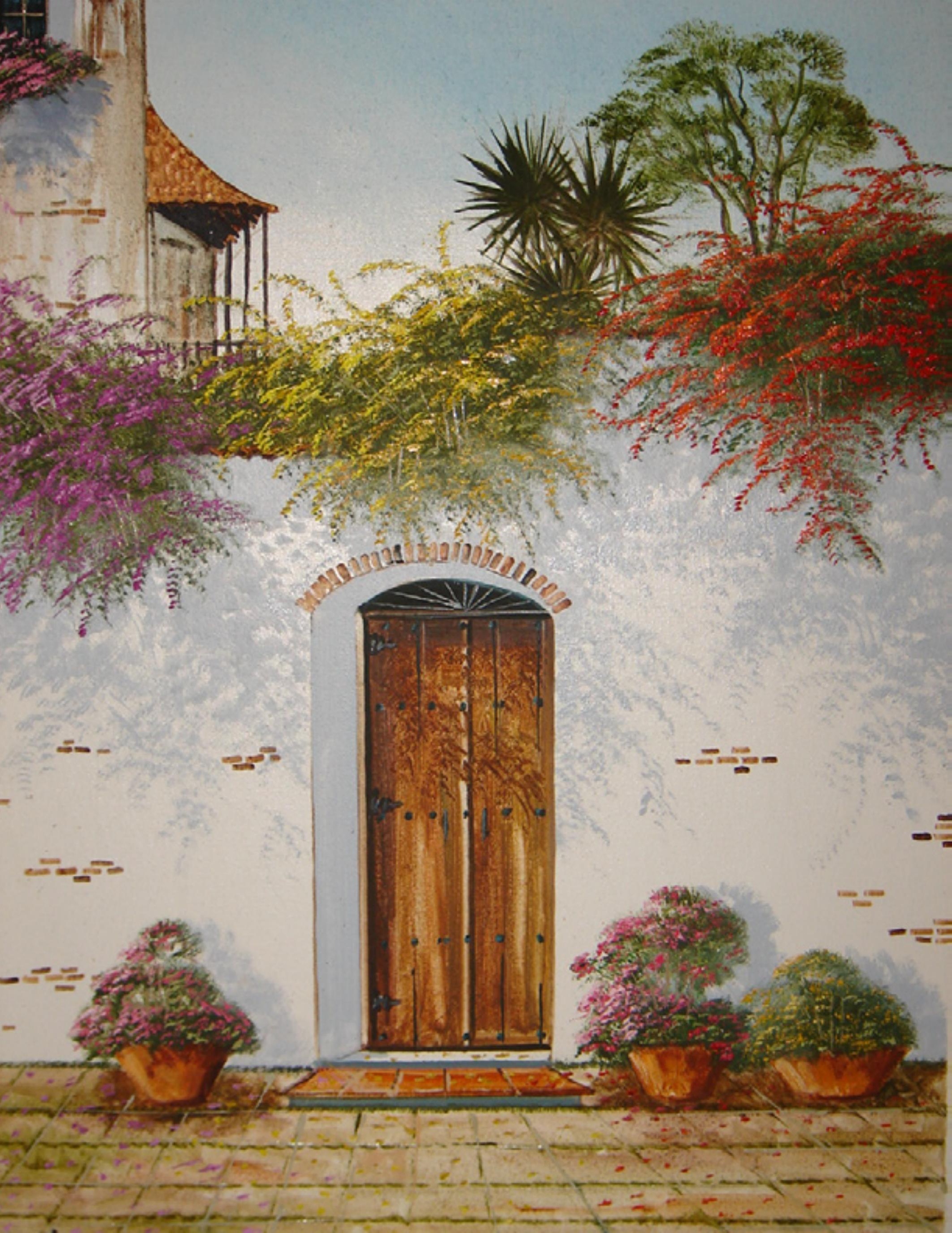




\section{4 algunos procesos del sentido gregario humano}

VITO VÉLIZ*

RESUMEN

En la historia del ser humano, las ciudades son un componente de la civilización. Pero la civilización tiene fallas que parcialmente salen a flote en los complejos urbanos. Dos ejemplos prehispánicos en Honduras son de ciudades que abusaron del ambiente y sucumbieron. Un ejemplo da muestras de buscar el ensanchamiento del espíritu, ubicándose sobre colinas y al mismo tiempo respetando las tierras planas y productivas. Hoy día nuestros gobiernos quieren llevarnos hacia la industrialización, pero se olvidan de los peldaños que necesariamente hay que escalar, antes de llegar a ese logro de la civilización. Uno de esos peldaños es tener alimentación suficiente y hasta de sobra, para que algunos pobladores puedan dedicarse a menesteres que no sean la producción de alimentos. Sin ningún interés por aprender del pasado, hoy día se está volviendo a utilizar tierra de vocación agrícola para urbanizaciones, para complejos comerciales e industriales y sin darle cabida a zonas de recreo. Debemos aprender de los errores y aciertos de nuestros antepasados, diseñar ciudades pequeñas, incorporar áreas de esparcimiento y buscar mecanismos para desarrollar esas ciudades pequeñas en cerros o colinas.

\section{ANTECEDENTES}

Al expresar opiniones sobre algún tema, debe recordarse que esas opiniones siempre van cargadas de ideas que tienen un historial y que las hemos hecho nuestras a lo largo de nuestra vida y de nuestras experiencias. Toda idea o concepto se perfila en nuestra mente con variadas acepciones y connotaciones.

La idea de "proceso" la voy a emplear aquí como aquellos acontecimientos, planificados o no, que marcaron un cambio en la vida del ser humano. Ya que es imposible abarcar todo, deseo que quede claro que se estará tomando en cuenta solamente "algunos" de esos tantos momentos que dejaron una huella en la trayectoria humana. Vamos a suponer en este ensayo que el ser humano trae dentro de sí el "sentido", el deseo o la necesidad de "gregarismo", de ser social, de vivir en grupo. Por fin, esa necesidad de vivir en grupo llevó a la humanidad al máximo gregarismo que son las ciudades.

El vocablo "ciudad", que ahora en particular nos interesa, tiene ascendencias griegas y latinas. Del griego "polis", que significa "ciudad", vienen las palabras "política”, "policía”. Del latín "urbs", que también significa "ciudad", vienen palabras como "urbano", "urbanización”. Las palabras "civil”, "civilizado", "civilización” vienen del latín "civis", que quiere decir "ciudadano". Todas estas relaciones nos indican que la palabra "civilización" está ligada a la de "ciudad". Se puede decir, entonces, que, con el pasar de los años, hemos venido

* Antropólogo-Arqueólogo, Asociación Copán y Observatorio Astronómico Centroamericano de Suyapa, Universidad Nacional Autónoma de Honduas (OACS/ UNAH). utilizando y entendiendo civilización como vida-en-la-ciudad (Whitehouse y Wilkins 1986: 9).

Aceptando la teoría del progreso o de la evolución cultural y para apreciar los procesos de la historia humana, es común hoy día pensar y hablar de los estadios o etapas de avance. Las más aceptadas son las cuatro etapas de: banda, tribu, cacicazgo y estado, que propusieron Sahlins y Service (1960) y Sanders y Price (1968). Se acepta y se pone en juego también las ideas o teorías de Gordon Childe sobre la Revolución Neolítica (1951: 59-86; 1954: 48-68) y sobre la Revolución Urbana (1951: 114-142; 1954: 89-112).

El concepto de "revolución neolítica" de Childe parte de lo que él consideró una forma de vida completamente distinta (Beals y Hoijer 1972: 299). Aunque no fue un paso súbito ni completo, la gente iba pasando poco a poco de la caza de animales y de la recolección de frutas y semillas a la domesticación de animales y al cultivo de plantas. Los seres humanos llegaron a depender menos de la naturaleza y pudieron formar poblados más permanentes y así lograron vivir en grupos que exigían menos terreno y pudieron vivir más unidos. Como resultado de su ubicación en puntos estratégicos: pasos obligados, a la orilla de ríos navegables o en zonas costeras, y por medio de las nuevas técnicas agrícolas, lograron excedentes que les permitieron a estos poblados no sólo ensanchar el comercio y aumentar su riqueza sino que también les permitieron sostener especialistas en muchas otras actividades, además de las agrícolas.

Los poblados continuaron creciendo hasta convertirse en ciudades. Este proceso trajo lo que Childe bautizó como "revolución urbana”. Se convirtió ésta en una nueva forma de vida que, por lo general, llegó acompañada de: fundición de metales, la rueda, la escritura, obras de riego, guerra, un más alto grado de organización, ciudades-estado, imperios y aumentó el número de gente dedicada a actividades específicas como la política, la religión, las artesanías, el comercio, etc.

Con los metales vinieron mejores instrumentos, mejores recipientes y un comercio más lejano. Con la fundición del hierro vino la "Revolución Industrial", que continúa todavía.

Lo anterior es una síntesis apretada de lo que básicamente sucedió en partes de Europa y del Medio Oriente. El desarrollo urbano en América llegó después de la domesticación o cultivo de varias plantas, especialmente del frijol, del ayote y, particularmente, del maíz. Pero en el Nuevo Mundo no existían animales grandes domésticos para realizar trabajo de campo. Esa deficiencia se enfrentó mejorando la organización de la fuerza humana. Ya que al metal no se le encontró un uso práctico, el urbanismo en América se logró bajo una tecnología neolítica, es decir, de piedra, sin metal (Beals y Hoijer 1972: 317).

Todo lo artificial en este planeta es artefacto, descubrimiento, invención, producto del ser humano. Uno de esos tantos productos o inventos es la civilización, el artefacto supremo de la humanidad que se desarrolla en un ambiente artificial y frágil y que se ha construido 
o desarrollado en un tiempo bastante corto (Whitehouse y Wilkins 1986: 10). El ser humano ha venido separándose del ambiente natural para construir y vivir encapsulado en su propio ambiente artificial, la ciudad.

\section{RESULTADOS}

No obstante todos estos cambios, tanto en el Viejo como en el Nuevo Mundo, la mayor parte de la gente continuó viviendo como en el neolítico: eran aldeanos que producían sus propios alimentos, que confeccionaban sus propios utensilios, su propia ropa, sus propias viviendas y contaban con pocos excedentes. Vivían vinculados a la tierra y poco les afectaba la vida de la ciudad (Beals y Hoijer 1972: 304).

Pero con el pasar de los años, ya en la actualidad, el agricultor próspero moderno vive prácticamente una vida urbana: no produce sus alimentos, no confecciona sus vestidos, no hace sus utensilios, produce para vender sus cosechas directamente por dinero y compra en la ciudad los alimentos, la ropa y todo artículo que necesita.

Así como cualquier otra práctica, institución o elemento cultural establecido por el ser humano puede tener sus debilidades o aspectos negativos, el urbanismo es uno de esos aspectos culturales que contiene grandes fragilidades. Con unos pocos ejemplos podremos ver no sólo la falta de adaptación que demostramos sino también los estragos y trastornos que nos está produciendo este artefacto de nuestra civilización o modo de vida actual: la concentración de gente puede traer desastres, puede causar disturbios sociales, puede haber epidemias, puede haber fallas tecnológicas desastrosas (derrumbes de edificios, accidentes eléctricos, etc.), ha tenido un crecimiento desordenado, los servicios que supuestamente debe ofrecer son muy deficientes, se experimenta un alto índice de criminalidad, existen altos grados de insalubridad, etc. Es tiempo ya que razonable e inteligentemente estudiemos el balance costo-beneficio que nos dejan las ciudades, tal como les hemos permitido desarrollarse.

\section{EJEMPLOS PREHISPÁNICOS EN HONDURAS}

La civilización o la vida urbana en América llegó con el cultivo del maíz. Pero las civilizaciones americanas se desarrollaron sin animales domésticos grandes. La energía necesaria para este desarrollo se logró mejorando la organización de la fuerza humana. Otro aspecto interesante es que estas civilizaciones disponían únicamente de una tecnología básicamente de piedra (sin metal). Aunque varias civilizaciones americanas conocieron y utilizaron algún metal, a éste nunca se le dio un uso práctico.

\section{LOS NARANJOS}

De acuerdo con los datos con que hasta la fecha se cuenta, en territorio hondureño, el urbanismo tuvo sus primeros pininos en el sitio arqueológico conocido hoy día como Los Naranjos (Baudez 1973), en la orilla norte del Lago de Yojoa (Figura 1). Fue aquí donde, alrededor del año 800 a.C. (antes de Cristo) apareció un grupo de nativos que, por las obras que realizaron, se presume tuvieron una organización social bastante sofisticada. En estas extensas planadas, excelentes para la agricultura, lograron construir varias pirámides muy grandes de adobe y unas fosas defensivas que, por sus dimensiones, demandaron mucha mano de obra bien controlada. Este fue un impulso que aparentemente vino por contacto con los olmecas del Istmo de Tehuantepec en México. En siglos posteriores, la ocu-
Figura No. 1. Mapa de la parte principal del sitio arqueológico Los Naranjos, orilla norte del Lago de Yojoa.

\section{GRUPO PRINCIPAL LOS NARANJOS}

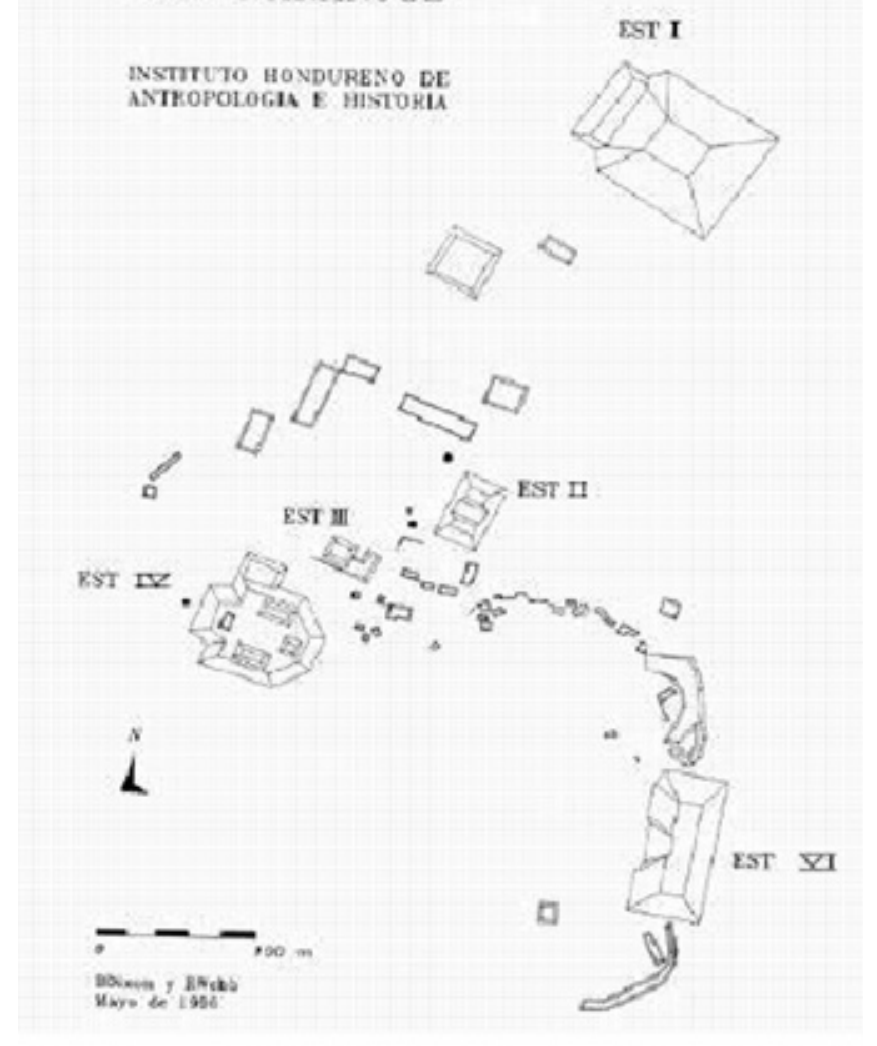

pación humana siguió creciendo en este asentamiento, pero ya no construyó edificios de las dimensiones de los primeros. Por falta de investigación, se desconoce todavía las razones del ocaso o abandono de esta localidad.

\section{COPÁN}

Hasta el momento (Fash y Agurcia 1996), la ciudad prehispánica por excelencia en Honduras es Copán (Figura 2). Los primeros restos arquitectónicos que se han encontrado en Copán son aproximadamente del año 300 d.C. y se han encontrado en la vega del Río Copán, en tierra plana, muy apta para la agricultura. El poblado fue creciendo, supuestamente alrededor de un individuo que conquistó la admiración y el servicio de los vecinos. De unos cuantos cienes, el poblado creció hasta llegar a ser una ciudad de aproximadamente unos 25,000 habitantes para el año 700 de nuestra era. Según la cronología de eventos que se ha logrado, se sabe que, una vez que el valle se saturó de viviendas, los vecinos comenzaron a buscar las faldas para construir sus viviendas. Para esta fecha, los copanecos habían ya aparentemente saturado con casas toda la vega o tierra plana disponible y habían tenido que esparcirse por las colinas adyacentes. Para sus pisos y repellos utilizaban un estuco que lo extraían de la quema de piedra de cal. Para el procesamiento de este último material necesitaban mucha leña. De modo que los mayas de Copán, con su ciudad, cubrieron e inhabilitaron la tierra plana, fértil y apta para la producción agrícola. Está también claro que con sus necesidades 
Figura No. 2. Mapa de los tres barrios constitutivos de la ciudad prehispánica de Copán: Las Sepulturas al noreste, el Grupo Principal al centro y El Bosque al suroeste.

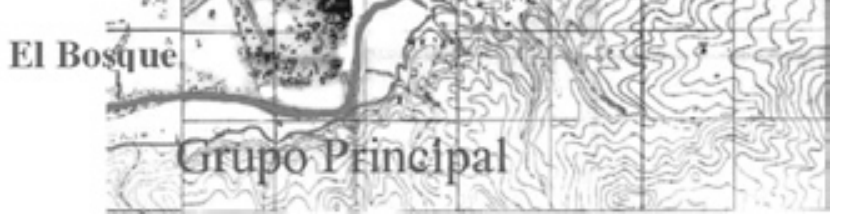

de madera para la construcción, para la producción de cal y para el cocimiento de sus alimentos, los mayas de Copán deforestaron los alrededores y seguramente se produjo entonces una gran erosión de los suelos más ricos (el humus superficial), dejando solamente laja o los suelos menos productivos. Todo esto bajó la producción agrícola, vinieron hambrunas y la gente sufrió desnutrición y enfermedades. El desastre fue tan grande que los gobernantes perdieron la credibilidad y la confianza de sus súbditos y tuvieron que huir o allí mismo los ejecutaron. Al hacer falta esa figura aglutinadora, la gente se dispersó y abandonó la ciudad. De esta manera, las prácticas civilizadas o de ciudad se abandonaron y luego la ciudad decayó. Así como Copán, casi todas las ciudades mayas de las Tierras Bajas o Centrales (El Petén) fueron abandonadas por ese tiempo (800-900 d.C.). Las primeras explicaciones para este abandono proponían causas únicas: terremotos, bajo rendimiento de la tierra, guerras internas, ataques externos, una epidemia. En años más recientes se ha considerado que quizá fue la conjunción de varias causas: la deforestación tanto para la preparación de alimentos como para la construcción y para la producción de cal ocasionó la erosión de los suelos, lo que a su vez dejó capas de tierra pobres para la agricultura, la falta de alimentos trajo no sólo epidemias sino también una pérdida de confianza y credibilidad en los gobernantes y, por ende, un descontento general en toda la población que trajo la muerte o el exilio de los líderes.

\section{CERRO PALENQUE}

Describiré brevemente otro ejemplo de una comunidad prehispánica hondureña. Me refiero a Cerro Palenque en el Valle de Sula, asentamiento que, por sus 26 hectáreas de extensión a través de cerros, se le puede perfectamente considerar como una ciudad (Figuras No. 3 y No. 4). Este sitio arqueológico lo han estudiado Joyce (1991) y Hendon y Lopiparo (2004). Floreció entre 850 d.C. y 1050 d.C. Una de las características de este asentamiento es que sus pobladores no buscaron las planadas del valle sino unas colinas en la parte suroeste del valle. Aquí vivieron unas 600 personas, levantaron edificios de piedra tallada, construyeron varias calzadas, erigieron un campo de pelota de mayores dimensiones que las del Campo de Pelota de Copán y edificaron una fosa de gran tamaño para almacenar agua. Fue un poblado que se asentó en la cima y en los lados de un cerro. La razón de este asentamiento en un cerro se ha venido interpretando como una función defensiva. Cualquiera que haya sido el objetivo, la realidad es que la gente optó por construir sus casas en un cerro y no en el llano aluvial, completamente plano. Esta circunstancia cierta-
Figura No. 3. Mapa de la sección principal del sitio arqueológico de Cerro Palenque en el Valle de Sula.

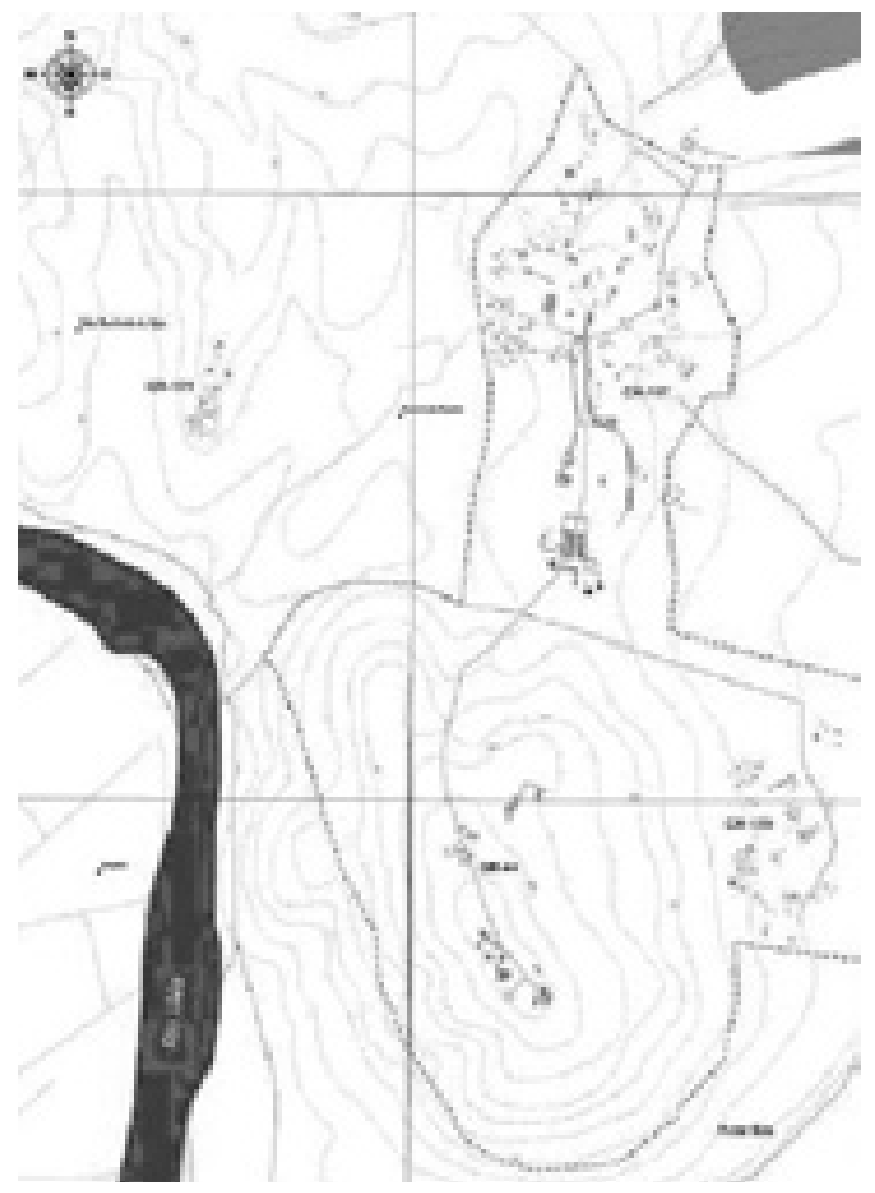

Figura No. 4. Vista de Cerro Palenque hacia el sur.

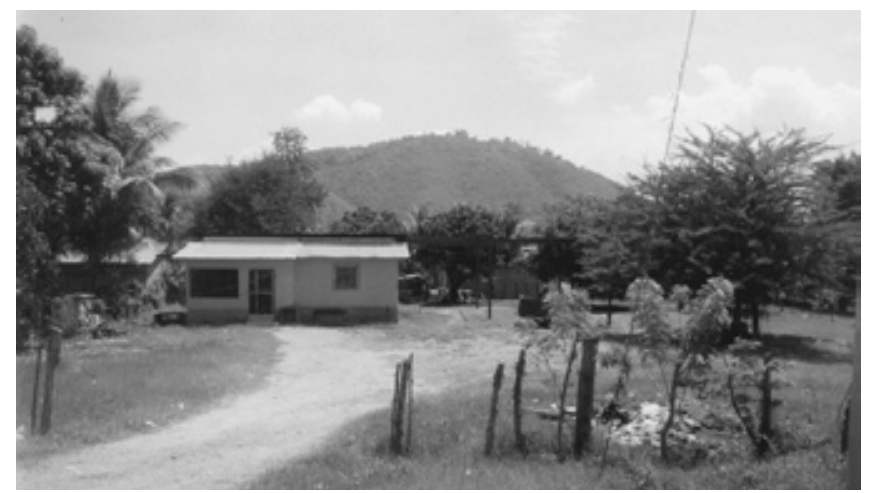

mente ha de haber traído muchos inconvenientes: dificultad para el abastecimiento de agua, el problema de tener que bajar a sus tierras de cultivo y tener que subir diariamente a sus casas de habitación. Pero dos ventajas están claras: lograron una panorámica espectacular del valle y liberaron mucha tierra del valle para el uso agrícola.

\section{REFLEXIÓN}

El estilo de vida urbano está influyendo cada vez más en la mentalidad y en la vida de los agricultores, campesinos o aldeanos. Ya no producen ni sus alimentos, ni sus vestidos, ni sus utensilios. Sus 
cosechas son para venderlas por dinero sonante y comprar alimentos, ropa y otros implementos. La vida del campo se está volviendo casi como la urbana. Nuestras instituciones, formas de pensar y valores se desarrollaron bajo una forma neolítica y esas prácticas son inadecuadas para la forma de vida urbana y para el ambiente de la revolución industrial, que comenzó con la fundición del hierro y continúa todavía desarrollándose (Beals y Hoijer 1972: 317).

Sin poner ninguna atención a los pasos que ha seguido la humanidad para llegar al nivel de civilización, nuestros gobiernos nos han venido empujando hacia ella. Pero un requisito no sólo es tener suficiente alimento sino más bien tener excedentes para que algunos miembros de la sociedad puedan dedicarse a otros menesteres, que no sean los de la agricultura. Solamente con excedentes de alimentos podremos entrar inteligentemente al proceso de industrialización y aprovechar, por lo menos, algunos de los beneficios de la misma. Tal como se ha mencionado antes, nosotros hemos estado entrando o tratando de entrar o siendo obligados a entrar a la urbanización y a la industrialización con mentalidad de campo, mentalidad de sobrevivencia. Este cambio ha sido acelerado y de ahí los distintos problemas urbanos, por no estar mentalizados a este modo de vida.

Es, además, oportuno comenzar a valorar las tierras que poseemos y darles el uso apropiado para despegar con algo mejor que la simple sobrevivencia. Es tarea de nuestros gobiernos propiciar políticas y medios realistas para que nuestra población haga producir la tierra. Esa producción debe ser primero para el consumo interno y luego para la exportación. Mientras estemos tratando de hacer las cosas al revés, estaremos yendo cuesta arriba. Es decir, mientras estemos tratando de industrializarnos sin tener qué comer, estaremos yendo contra la corriente. ¡Lo primero, primero! Ojalá que los esfuerzos del "ordenamiento territorial" sean realistas y se pongan en práctica.

Los estudios antropológicos pasados, sobre las ciudades, se han concentrado en los problemas, aspectos negativos o mal ajustes que los inmigrantes han encontrado en las ciudades. En su afán por identificar las maneras en que los migrantes se han enfrentado a la vida en la ciudad, algunos antropólogos se han interesado más por estudiar aspectos como: la falta de acoplamiento a la vida en la ciudad; los problemas, deterioro y desunión que ha traído a la vida familiar; pérdida de la religiosidad; aumento en la delincuencia. Los que llegan a la ciudad se han encontrado con un ambiente frío, impersonal, mecánico, inmoral y hostil. Todos sufren una descomposición social que en antropología se le llama "choque cultural" (Lewis 1970: 413-414). Otros antropólogos se han enfocado en el plan físico o disposición de las ciudades (Foster 1960: 34-49).

No obstante todos los problemas y todas las circunstancias adversas, el movimiento de la población rural hacia las ciudades ha sido tan alarmante, desde el siglo pasado, que en 1984 ya se predecía que para el 2000 un $40 \%$ del total de la población de los países menos desarrollados sería urbana (Odell 1984: 121). Esto implica un crecimiento inusitado de las ciudades. Crecimiento que, por desgracia, ha sido desordenado, sin planificación y sin ningún control de parte de las autoridades edilicias. No se han aprovechado y, en muchos casos, más bien se han destruido los distintos escenarios hermosos y atractivos naturales que nos ha prodigado la madre naturaleza como: playas, ríos, bosques, parajes hermosos y carreteras. Paisajes estos que, en vez de mantenerse limpios y atractivos, los hemos convertido en basureros (Butler 1959:159).

Por lo menos en nuestro medio hondureño, en los complejos habitacionales, ya no se deja ningún espacio para el esparcimiento de la gente. ¡Abramos los ojos! Concienticémonos de esta gran desventaja para la población en general y de la avaricia de los que desarrollan estos complejos habitacionales y comencemos a exigir parques y áreas de recreo cerca de nuestras casas. Revisemos y comprobemos en qué colonias y barrios de Tegucigalpa, o de otras ciudades del país, los planificadores han dejado o las autoridades urbanas han exigido "áreas verdes”. Debe buscarse no sólo el desarrollo físico ordenado y atractivo de las ciudades sino también el enriquecimiento de la vida de sus moradores. El hecho de vivir dentro de cuatro paredes y rodeado de sólo casas y edificios no provee ningún ensanchamiento al espíritu creador y expansivo del ser humano. Las áreas de recreo enriquecen al individuo y a la comunidad, brindándoles oportunidades de admirar bellezas naturales y de ensanchar y de recrear su espíritu forjador (Butler 1959: 163).

Como seres sociales y productos de sucesos históricos, los humanos debemos institucionalizar la costumbre de revisar y de aprender del pasado. Lamentable es la situación porque raras veces nos remontamos al pasado y muy poco es lo que aplicamos de ese pasado. Pero los esfuerzos deben ser cada vez más conscientes y es por eso que deseo traer o poner a consideración lo poco que hemos aprendido de nuestros ilustres antepasados.

Por lo menos tres lecciones claras nos quedan de las someras consideraciones que hicimos de algunos de nuestros restos prehispánicos: 1) Debemos respetar aquellas tierras planas, fértiles y aptas para la agricultura, 2) Debemos planificar y seleccionar conscientemente la ubicación de los centros de población, fijar topes de población y no permitir su crecimiento desordenado y 3) Debemos reforestar y respetar los pocos bosques que todavía nos quedan para no precipitar la erosión de los suelos ni perder la humedad en los mismos ni la eventual extinsión de nuestras fuentes de agua. Adelantémonos a las catástrofes que se avisoran.

Pero ¿qué es lo que ha venido y continúa sucediendo? Casi todos los poblados y ciudades están en tierras planas, excelentes para la agricultura. Los urbanizadores prefieren los ahorros que representan esas tierras planas y así las ciudades se han venido desarrollando en las tierras agronómicamente más productivas (Barrons 1978: 90; Mumford 1956: 383-384, 391-392, 394). No es necesario visitar otros países para ver cómo los poblados siguen desarrollándose en nuestras mejores parcelas y en nuestros fértiles valles. Hoy día vemos como, en esa tierra llana, se construyen centros urbanos, centros comerciales e industriales, maquilas, etc., todo de una sola planta y en las tierras más aptas para la producción agrícola (Figuras No. 5 y No. 6; Barrons 1978: 90). Con toda seguridad que esas tierras de vocación agrícola las estaremos deseando dentro de pocas generaciones.

Figura No. 5. Vista de maquilas en el Valle de Sula, Villa Nueva, Cortés.

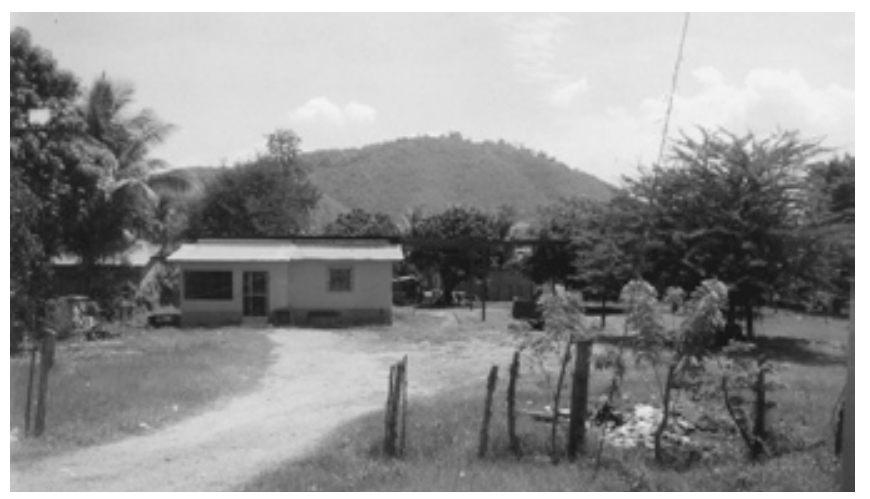


Figura No. 6. Vista hacia el oeste del Centro Comercial Plaza en Tegucigalpa.

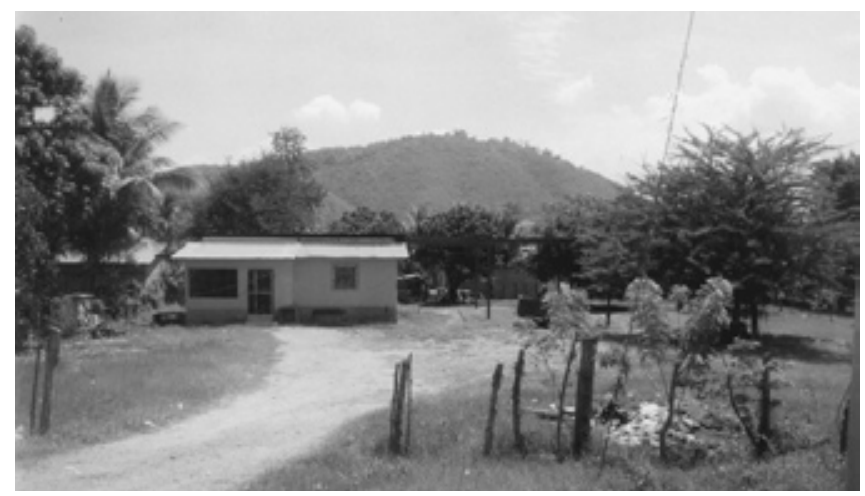

\section{CONCLUSIÓN}

De todo lo anterior se puede aprender que no todo lo que hemos inventado es provechoso y que no todos los adelantos tecnológicos son positivos. Esto nos lleva a tener que conscientemente comenzar a revisar nuestros valores o todo aquello que hemos venido considerando bueno o ventajoso para la humanidad. Mi conclusión es que las ciudades desmesuradas y sin planificación nos están llevando a niveles infrahumanos cada vez más bajos. Tenemos que replantearnos otro tipo de ciudad (Mumford 1956: 396-397).

Parte del bienestar y de la felicidad humana son el aprovechamiento y el disfrute de las riquezas y bellezas naturales. Para lograr eso tenemos que valorarlas, conservarlas y convivir con ellas. De ahora en adelante debemos de pensar en ciudades más pequeñas para evitar desastres y debemos buscar los mecanismos adecuados para que estas nuevas ciudades se desarrollen en colinas (Figuras 7 y 8), dejando así libres los predios planos para la agricultura e incorporar, de manera funcional, todo servicio, incluyendo áreas recreativas.

El desastre en Copán vino por no haber respetado los bosques y por haber utilizado para viviendas terreno propio para la agricultura. Vimos también el modelo de Cerro Palenque, cuyos habitantes optaron por liberar terrenos planos y construir sus viviendas en la cima y en los lados de un cerro.

Aprendamos de nuestro pasado. Optemos por planificar y estructurar bien nuestras futuras ciudades. Prefiramos ciudades pequeñas. Elijamos la economía del terreno, ubicando nuestras ciudades en colinas o cerros para que después no sintamos la falta de terreno para la producción de alimentos.

Figura No. 7. Vista parcial de Villanueva, Cortés, desarrollándose hacia las colinas.

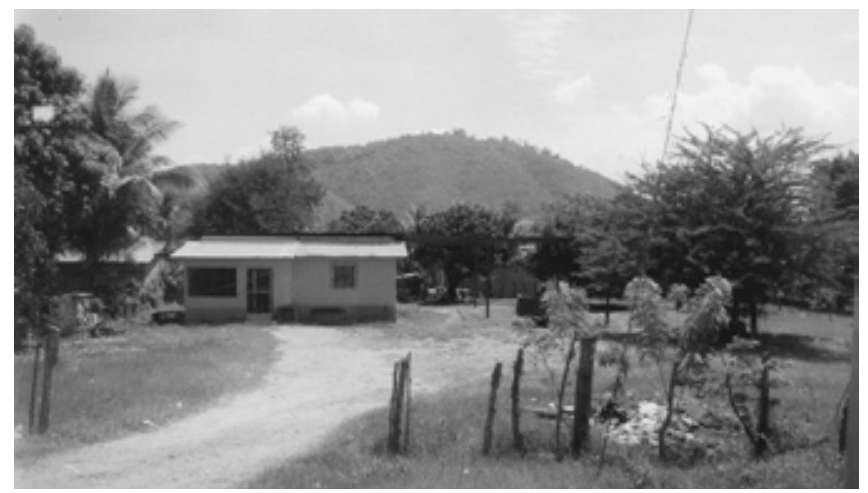

Figura No. 8. Vista de, poblado reciente, ubicado en el lado de una colina, cerca de Manacales, Carretera del Norte, Valle de Sula.

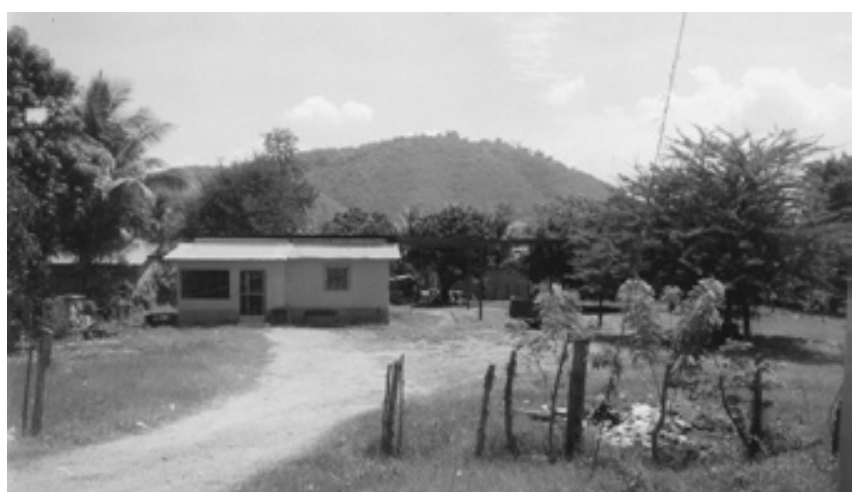

Soy de la opinión que, así como nos introdujimos en esto del urbanismo y de la civilización, también podemos salirnos, si nos proponemos. Si queremos disfrutar de vidas más sanas y seguras, tenemos que comenzar a esforzarnos por volver a estilos de vida más sencillos. La deforestación, las desigualdades abismales en riqueza, los maremotos (como el reciente en Surasia), los desajustes sociales, la corrupción administrativa, etc., etc. todos estos trastornos son consecuencia de nuestro estilo de vida civilizado porque éste apunta únicamente hacia el consumo y la acumulación de riqueza. Ni el mundo natural ni el mundo social tienen la capacidad de resistir esta voracidad y, por eso, los esquemas y valores mentales tienen que cambiarse; de lo contrario, vamos vertiginosamente hacia el desastre.

\section{BIBLIOGRAFÍA}

Barrons, Keith C.

1978 La Alimentación en el Mundo del Futuro: Pautas para una Mayor Productividad. EDISAR, S.R.L., Buenos Aires.

Baudez, Claude F. y Piérre Becquelin

1973 Archéologie de Los Naranjos, Honduras. Mission Archéologique et Ethnologique Francaise au Méxique. México.

Beals, Ralph y Harry Hoijer

1972 Introducción a la Antropología. Traductor Juan Martín Ruiz-Werner. Aguilar, Madrid.

Butler, George D.

1959 Introduction to Community Recreation: Prepared for the National Recreation Association. Tercera Edición. McGraw-Hill Book Company, Inc., Nueva York.

Childe, Vere Gordon

1951 Man Makes Himself. The New American Library, Nueva York.

1954 What Happened in History. Penguin Books, Baltimore.

Fash, William y Ricardo Agurcia

1996 Visión del Pasado Maya: Proyecto Arqueológico Acrópolis de Copán. Asociación Copán.

Foster, George M. Chicago.

1960 Culture and Conquest: America's Spanish Heritage. Quadrangle Books,

Hendon, Julia y Jeanne Lopiparo

2004 Investigaciones Recientes en Cerro Palenque, Cortés, Honduras. VII Seminario de Antropologia de Honduras: 187-195. Instituto Hondureño de Antropologia e Historia, Tegucigalpa.

Joyce, Rosemary A.

1991 Cerro Palenque: Power and Identity on the Maya Periphery. University of Texas Press, Austin.

Lewis, Oscar

1970 Anthropological Essays. Random House, Nueva York.

Mumford, Lewis

1956 The Natural History of Urbanization. En Man's Role in Changing the Face of the Earth, Vol. I. William L. Thomas, Jr. Editor: 382-398. The University of Chicago Press.

Odell, Rice 
1984 La Revolución Ambiental: Estudios sobre la Contaminación y Protección del Medio Ambiente. Editorial Fraterna, Buenos Aires.

Richards, Janet y Mary Van Buren

2000 Order, Legitimacy, and Wealth in Ancient States. Cambridge University Press, Cambridge.

Sahlins, Marshall D. y Elmer R. Service, Editores
1960 Evolution and Culture. Ann Arbor, University of Michigan Press.

Sanders, William T. y Barbara J. Price

1968 Mesoamerica: The Evolution of a Civilization. Random House, New York.

Whitehouse, Ruth y John Wilkins

1986 The Making of Civilization: History Discovered through Archaeology. Collins, Londres. 